\title{
A gas-liquid interface synthesis in polyoxometalate chemistry: potential bag filter for volatile organic amines
}

\author{
VADDYPALLY SHIVAIAH, N TANMAYA KUMAR and SAMAR K DAS* (D) \\ School of Chemistry, University of Hyderabad, Hyderabad, Telangana 500 046, India \\ E-mail: skdas@uohyd.ac.in
}

MS received 24 November 2017; revised 1 February 2018; accepted 17 February 2018; published online 22 March 2018

\begin{abstract}
Diffusion of piperidine and pyridine into an acidified aqueous solution of $\mathrm{Na}_{2} \mathrm{MoO}_{4}$, yield compounds $\left[(\mathrm{pipH})_{4}\right]\left[\mathrm{Mo}_{8} \mathrm{O}_{26}\right] \cdot 4 \mathrm{H}_{2} \mathrm{O}\left(\right.$ pip $=$ piperidine $\left.=\mathrm{C}_{5} \mathrm{H}_{11} \mathrm{~N}\right)(\mathbf{1})$ and $\left[(\mathrm{pyH})_{4}\right]\left[\mathrm{Mo}_{8} \mathrm{O}_{26}\right](\mathrm{py}=$ pyridine $\left.=\mathrm{C}_{5} \mathrm{H}_{5} \mathrm{~N}\right)(\mathbf{2})$, respectively. Compound 1 possesses supramolecular 3-D network and the relevant connectivity pattern generates channels of approximate dimensions of $10.76 \times 11.57 \AA^{2}$, in which the piperidinium cations are located as guests. Multidimensional supramolecular frameworks (3-D in compound 1 and 2-D layer type of network in compound 2) have been made possible, as the organic cations and polyoxometalate (POM) anions are glued together by significant hydrogen bonding interactions. The synthesis of compounds $\mathbf{1}$ and $\mathbf{2}$ provides a unique 'gas-liquid' synthetic route in POM chemistry that result in organicinorganic hybrid materials with structural diversities. This synthetic approach, first time in POM chemistry, can be described as a potential bag filter for volatile organic amines.
\end{abstract}

Keywords. Volatile organic amines; hydrogen bonding; Lindqvist-type isopolyanions; gas-liquid diffusion.

\section{Introduction}

Polyoxometalates (POMs) were reported over 200 years ago. However, even today POMs have attracted augmented attention because of their potential applications in interdisciplinary research areas like catalysis, materials science, medicine, biochemical analysis, etc. ${ }^{1}$ One of the recent advances in POM chemistry is the synthesis of organic-inorganic hybrid materials that are important in the context of their material properties as well as framework-like stable construction having well-defined channels and cavities. ${ }^{2,3}$ An assortment of reviews presented in the recent years give a comprehensive account of a range of aspects including synthetic strategies, types and applications of these polyoxometalate based frameworks. ${ }^{4}$ A review by Ya-Qian Lan et al., presents an important and emerging field in the polyoxometalate based framework materials, that is, polyoxometalates based metal-organic frameworks (MOFs). ${ }^{5}$ These materials have got the advantage of both POMs and the MOFs and hence have got a wide range of applications. ${ }^{5}$ The POM-based hybrid materials are generally synthesized by hydrothermal techniques, that normally use high

\footnotetext{
*For correspondence
}

temperature. ${ }^{6}$ Simple wet syntheses are also known to generate such framework type hybrid POM compounds ${ }^{7}$ but are very rare. There are reports on photochemical reactions, which result in the isolation of POM-based compounds. ${ }^{8 a}$ Conventional synthesis also provides some POM-based organic-inorganic compounds that can be used as photoactive systems. ${ }^{8 \mathrm{~b}-\mathrm{g}}$ We introduce a new synthetic strategy/route here, namely, a 'gas-liquidinterface' reaction that can simply be described as the diffusion of volatile organic amines (e.g., pyridine and piperidine in the present work) into an acidified aqueous molybdate solution (Schemes 1 and 2). The above said volatile organic amines are released into the environment from various sources including some industrial processes, like, steel manufacture processing of oil shale, coal gasification and incinerators. ${ }^{9}$ These amines have less reports of being carcinogenic to humans, but are highly documented as harmful to various animals. They are proven to be neurotoxic, genotoxic and clastogenic in nature. ${ }^{10}$ Volatile organic amines are extreme pollutants and they are the source of dreadful health and environmental problems due to their odorous and toxic characteristics owing to their existence in stored meat, food, dustbins, and sewers. ${ }^{11,12}$ High doses of amines can promote uncontrolled reactions in the human body 
and can initiate acute or delayed toxicities to nervous systems, hematopoietic systems, human skin, urinary systems, respiratory systems thus causing cancer, strokes or other diseases. ${ }^{13-16}$ Volatile amines can form nitrosamines, which are cancer-causing substances, ${ }^{17,18}$ and thus, trapping of volatile organic amines is a critical need in order to monitor the real environment. ${ }^{19}$

The basic idea of this synthetic route lies in the fact that an aqueous molybdate solution, on acidification, gives rise to a range of isopolyanions, e.g., $\left[\mathrm{Mo}_{6} \mathrm{O}_{19}\right]^{2-}$, $\left[\mathrm{Mo}_{8} \mathrm{O}_{26}\right]^{4-},\left[\mathrm{Mo}_{36} \mathrm{O}_{112}\left(\mathrm{H}_{2} \mathrm{O}\right)_{18}\right]^{8-}$, etc., depending on various parameters such as $\mathrm{pH}$, concentration of the relevant POM solution and temperature. ${ }^{1 \mathrm{c}, 20}$ Since these polyanions (formed in POM solution) are anionic in nature, they need obligatory cations for their successful isolation. Volatile organic amines having "N" donors can be diffused to such aqueous acidic POM solution, in which organic cations are formed by protonation of respective "N" donor atoms and the relevant POM cluster can be isolated as ion pair compounds, that can be described as inorganic-organic hybrid materials (Schemes 1 and 2). Previously reported organic aminebased POMs were synthesized by hydrothermal techniques. ${ }^{21}$ There are various reports on the compounds containing $\left[\mathrm{Mo}_{8} \mathrm{O}_{26}\right]^{4-}$ and organic cations. ${ }^{22}$ The compound $\mathbf{1}$ is also known earlier, ${ }^{23}$ but in that report, it is synthesized by using the conventional method. Similarly, various other inorganic-organic hybrids

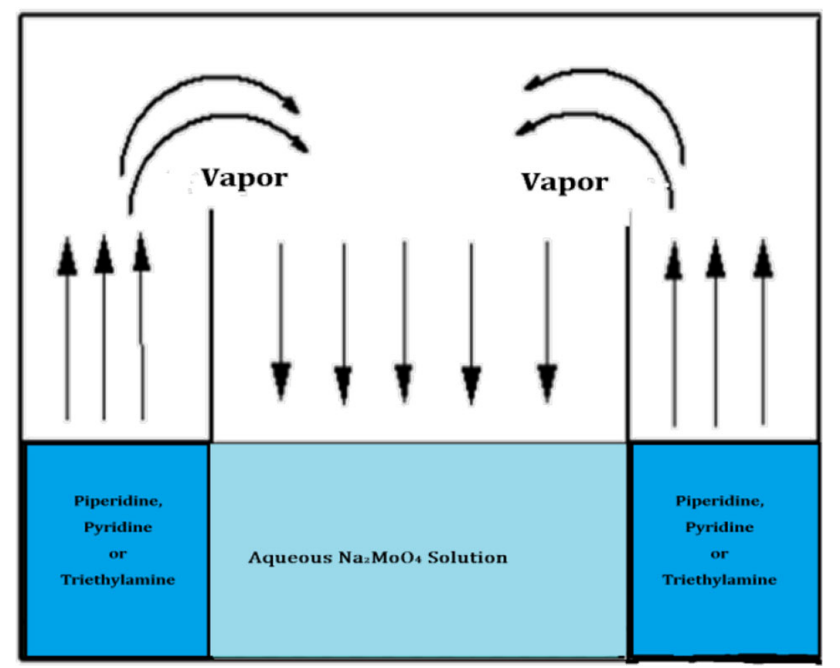

Scheme 1. The general schematic synthetic 'gas-solid-interface' procedure for the compounds $\mathbf{1}$ and $\mathbf{2}$.

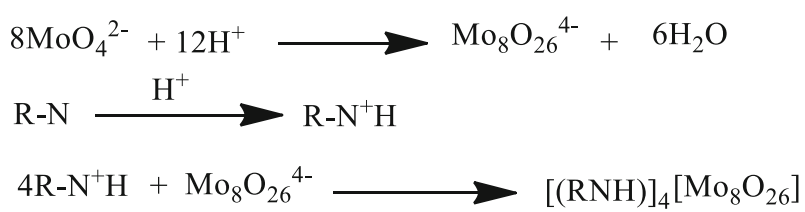

Scheme 2. Reaction route for the synthesis of the compounds $\mathbf{1}$ and $\mathbf{2}$. including diverse polyoxometalates with piperidines ${ }^{24}$ and pyridines ${ }^{25}$ have been reported. To the best of our knowledge, this is the first report, where the volatile amines are made to interact with in situ formed polyoxometalates, through the vapour-diffusion method, which makes them being used as a potential bag to isolate volatile amines from a mixture of organic amine systems.

Herein, we report two hybrid inorganic-organic compounds $\left[(\mathrm{pipH})_{4}\right]\left[\mathrm{Mo}_{8} \mathrm{O}_{26}\right] \cdot 4 \mathrm{H}_{2} \mathrm{O}(\mathbf{1})$ and $\left[(\mathrm{pyH})_{4}\right]\left[\mathrm{Mo}_{8}\right.$ $\left.\mathrm{O}_{26}\right]$ (2) that are isolated by above-described gas-liquid interface method (see Schemes 1 and 2). More specifically, compounds $\mathbf{1}$ and $\mathbf{2}$ were prepared by dissolving $\mathrm{Na}_{2} \mathrm{MoO}_{4}$ in distilled water in a small beaker, acidified to $\mathrm{pH}$ range of $2-2.2$ with concentrated $\mathrm{HCl}$. This small beaker was then kept in another large sized beaker containing amines (piperidine or pyridine) as shown in Scheme 1, resulting in crystals of $\mathbf{1}$ and $\mathbf{2}$ of respective systems. Compounds $\mathbf{1}$ and $\mathbf{2}$ were characterized by FT-IR, elemental analysis and unambiguously by single crystal X-ray diffraction techniques. We have described a detailed supramolecular analyses of compounds $\mathbf{1}$ and 2 in the perspective of relevant hydrogen bonding interactions.

\section{Experimental}

\subsection{Materials and Physical Methods}

All the chemicals were received (from Fisher Scientific) as reagent grade and used without any further purification. Elemental analyses were determined by FLASH EA series 1112 CHNS analyzer. Infrared spectra of solid samples were obtained as $\mathrm{KBr}$ pellets on a JASCO-5300 FT-IR spectrophotometer.

\subsection{Synthesis}

2.2a Synthesis of $\left[(\text { pip })_{4}\right]\left[\mathrm{Mo}_{8} \mathrm{O}_{26}\right] \cdot 4 \mathrm{H}_{2} \mathrm{O}(\mathbf{1})$ (pip = piperidine $):$ Sodium molybdate $(5.0 \mathrm{~g}, 20.67 \mathrm{mmol})$ was dissolved in $50 \mathrm{~mL}$ of water followed by the addition of $10 \mathrm{~mL}$ of glacial acetic acid with stirring at room temperature. This reaction mixture was then acidified to $\mathrm{pH}$ 2 by the drop-wise addition of conc. $\mathrm{HCl}$, which results in a clear solution. The resultant reaction mixture was filtered into a $100 \mathrm{~mL}$ beaker. This $100 \mathrm{~mL}$ beaker was kept in a $250 \mathrm{~mL}$ beaker containing piperidine. Then the experimental setup was closed by aluminium foil and kept at room temperature. The crystal growth started within two hour duration time. After two days, the crystals were filtered, washed with cold distilled water and dried at room temperature. Yield: $2 \mathrm{~g}(48.23 \%$ based on Mo). IR (KBr pellet) $\left(\mathrm{v} / \mathrm{cm}^{-1}\right)$ : 3533(b), 3136(w), 1606(s), 1454(s), 1377(m), 1267(w), 1174(m), 1024(w), 918(vs), 843(s), 715(s), 524(w), 421(w). Elemental analysis: Calcd. (\%). C, 15.01; H, 3.52; N, 3.50. Found (\%): C, 14.54; H, 2.95; N 3.32 . 
2.2b Synthesis of $\left[(p y H)_{4}\right]\left[\mathrm{Mo}_{8} \mathrm{O}_{26}\right](2)$ (py $=$ pyridine): Sodium molybdate $(3.5 \mathrm{~g}, 14.46 \mathrm{mmol})$ was dissolved in $50 \mathrm{~mL}$ of water followed by the addition of $10 \mathrm{~mL}$ of glacial acetic acid with stirring at room temperature. This reaction mixture was acidified to $\mathrm{pH} 2.2$ by the drop-wise addition of conc. $\mathrm{HCl}$, which results almost in the clear solution. This mixture was filtered into a $100 \mathrm{~mL}$ beaker. This beaker was then kept in $250 \mathrm{~mL}$ beaker containing pyridine and it was then closed by aluminum foil and kept at room temperature. The crystal growth started within the two hours duration of time. After $24 \mathrm{~h}$, these crystals were filtered, washed with cold distilled water and dried at room temperature. Yield: $2.1 \mathrm{~g}(77.22 \%$ based on Mo). IR (KBr pellet) $\left(\mathrm{v} / \mathrm{cm}^{-1}\right)$ : 3105(b), 1604(s), 1529(s), 1485(s), 1332(m), 1240(m), 1201(s), 1167(s), 1049(m), 947(vs), 682(w). Elemental analysis: Calcd. (\%). C, 15.97; H, 1.60; N, 3.73. Found (\%): C, 15.38; H, 1.95; N 3.10 .

\subsection{Crystallography}

Single crystals of compounds $\left[(\mathrm{pipH})_{4}\right]\left[\mathrm{Mo}_{8} \mathrm{O}_{26}\right] \cdot 4 \mathrm{H}_{2} \mathrm{O}$ (1) and $\left[(\mathrm{pyH})_{4}\right]\left[\mathrm{Mo}_{8} \mathrm{O}_{26}\right]$ (2) were measured at room temperature on a Bruker SMART APEX CCD area detector system $[\lambda(\mathrm{Mo} \mathrm{K} \alpha)=0.7103 \AA]$ graphite monochromator, 2400 frames were recorded with an $\omega$ scan width of $0.3^{\circ}$, each for $8 \mathrm{~s}$, crystal-detector distance $60 \mathrm{~mm}$, collimator $0.5 \mathrm{~mm}$. Data reduction was done by SAINTPLUS, ${ }^{26}$ absorption correction was performed using an empirical method (SADABS) structure solution using SHELXS-97 ${ }^{27}$ and refined using SHELXL-97. ${ }^{28}$ All non-hydrogen atoms were refined anisotropically. The crystallographic data and structure refinement parameters for compounds $\mathbf{1}$ and $\mathbf{2}$ are presented in Table 1.

\section{Results and Discussion}

\subsection{Synthesis}

In this work, we have provided a unique synthetic route to generate a polyoxometalate $(\mathrm{POM})$ cluster $\left[\mathrm{Mo}_{8} \mathrm{O}_{26}\right]^{4-}$. We have called it a 'gas-liquid-interface' approach in POM chemistry (Scheme 1). In contrast to normal wet synthesis, the present route is much more

Table 1. Crystal data and structure refinement for compounds $\mathbf{1}$ and $\mathbf{2}$.

\begin{tabular}{|c|c|c|}
\hline & Compound 1 & Compound 2 \\
\hline Empirical formula & $\mathrm{C}_{20} \mathrm{H}_{56} \mathrm{~N}_{4} \mathrm{O}_{30} \mathrm{Mo}_{8}$ & $\mathrm{C}_{20} \mathrm{H}_{24} \mathrm{Mo}_{8} \mathrm{~N}_{4} \mathrm{O}_{26}$ \\
\hline Formula weight & 1600.21 & 1503.95 \\
\hline Temperature & $273(2) \mathrm{K}$ & $273(2) \mathrm{K}$ \\
\hline Wavelength & $0.71073 \AA$ & $0.71073 \AA$ \\
\hline $\begin{array}{l}\text { Crystal system, space group } \\
\text { Unit cell dimensions }\end{array}$ & Monoclinic, P 21/n & Triclinic, $\mathrm{P}-1$ \\
\hline $\mathrm{a}$ & $12.8945(6) \AA$ & $9.5680(19) \AA$ \\
\hline $\mathrm{b}$ & $9.2935(5) \AA$ & 9.949(2) $\AA$ \\
\hline $\mathrm{c}$ & $19.1953(9) \AA$ & $10.659(2) \AA$ \\
\hline$\alpha$ & $90^{\circ}$ & $83.70(3)^{\circ}$ \\
\hline$\beta$ & $92.4670(1)^{\mathrm{o}}$ & $76.36(3)^{\circ}$ \\
\hline$\gamma$ & $90^{\circ}$ & $69.01(3)^{\circ}$ \\
\hline Volume & $2298.1(2) \AA^{3}$ & 1014.6(3) $\AA^{3}$ \\
\hline Z, Calculated density & $2,2.312 \mathrm{Mg} / \mathrm{m}^{3}$ & $1,2.714 \mathrm{Mg} / \mathrm{m}^{3}$ \\
\hline Absorption coefficient & $2.203 \mathrm{~mm}^{-1}$ & $2.735 \mathrm{~mm}^{-1}$ \\
\hline $\mathrm{F}(000)$ & 1560 & 716 \\
\hline Crystal size & $0.42 \times 0.35 \times 0.21 \mathrm{~mm}^{3}$ & $0.50 \times 0.50 \times 0.45 \mathrm{~mm}^{3}$ \\
\hline Theta range for data collection & 1.87 to $28.27^{\circ}$ & 1.97 to $28.69^{\circ}$ \\
\hline Limiting indices & $\begin{array}{l}-17<=\mathrm{h}<=17 \\
-12<=\mathrm{k}<=12 \\
-25<=l<=25\end{array}$ & $\begin{array}{c}-12<=\mathrm{h}<=12 \\
-13<=\mathrm{k} z<=13 \\
-14<=l<=14\end{array}$ \\
\hline Reflections collected/unique & 26037 / 5496 & 10538 / 4332 \\
\hline & {$[\mathrm{R}($ int $)=0.0695]$} & {$[\mathrm{R}($ int $)=0.0275]$} \\
\hline Completeness to theta & $28.2796 .4 \%$ & $28.6991 .1 \%$ \\
\hline Refinement method & Full-matrix least-squares on $\mathrm{F}^{2}$ & Full-matrix least- squares on $\mathrm{F}^{2}$ \\
\hline Data/restraints/parameters & $5496 / 0 / 281$ & 4332 / 0 / 264 \\
\hline Goodness-of-fit on $\mathrm{F}^{2}$ & 1.107 & 1.137 \\
\hline Final $\mathrm{R}$ indices $[\mathrm{I}>2 \operatorname{sigma}(\mathrm{I})]$ & $\begin{array}{l}\mathrm{R} 1=0.0281 \\
\mathrm{wR} 2=0.0756\end{array}$ & $\begin{array}{l}\mathrm{R} 1=0.0251 \\
\mathrm{wR} 2=0.0631\end{array}$ \\
\hline $\mathrm{R}$ indices (all data) & $\begin{array}{c}\mathrm{R} 1=0.0296 \\
\mathrm{wR} 2=0.0767\end{array}$ & $\begin{array}{c}\mathrm{R} 1=0.0267 \\
\mathrm{wR} 2=0.0642\end{array}$ \\
\hline Largest diff. peak and hole & 1.097 and $-0.894 \mathrm{e} . \AA^{-3}$ & 0.556 and $-1.127 \mathrm{e} . \AA^{-3}$ \\
\hline
\end{tabular}


easy and clean. Compound $\left[(\mathrm{pipH})_{4}\right]\left[\mathrm{Mo}_{8} \mathrm{O}_{26}\right] \cdot 4 \mathrm{H}_{2} \mathrm{O}$ (1), synthesized in the present work in a gas-liquid interface reaction (Schemes 1 and 2), was synthesized earlier in a wet synthesis, by the reaction of sodium molybdate and piperidine in an aqueous solution and concerned single crystals were obtained from $\mathrm{CH}_{3} \mathrm{NO}_{2}$ solution by recrystallization. ${ }^{23 a}$ We feel that this gas-liquidinterface approach is not only simple and clean but also it does not need a recrystallization step. Moreover, we got much more well-resolved structure of compound $\mathbf{1}$ in the present study compared to that reported earlier. ${ }^{23 a}$ We maintained the $\mathrm{pH}$ of sodium molybdate solution 2.0 and obtained octamolybdate type POM cluster anion as shown in equation 1 . The in situ formed octamolybdate $\left[\mathrm{Mo}_{8} \mathrm{O}_{26}\right]^{4-}$ can be isolated as piperidinium salt, $\left[(\mathrm{pipH})_{4}\right]\left[\mathrm{Mo}_{8} \mathrm{O}_{26}\right] \cdot 4 \mathrm{H}_{2} \mathrm{O}(\mathbf{1})$, when piperidine was diffused to the concerned solution (Scheme 1).

$8 \mathrm{MoO}_{4}^{2-}+12 \mathrm{H}^{+} \rightarrow\left[\mathrm{Mo}_{8} \mathrm{O}_{26}\right]^{4-}+6 \mathrm{H}_{2} \mathrm{O}$

We have rationalized this gas-liquid interface synthesis approach by using another volatile amine, pyridine and isolated compound $\left[(\mathrm{pyH})_{4}\right]\left[\mathrm{Mo}_{8} \mathrm{O}_{26}\right](2)$.

The uniqueness of this gas-liquid synthesis is that, at the experimental condition (an aqueous molybdate solution at a low $\mathrm{pH}$ ) that we used, formation of several polyoxometalate clusters is possible, such as, hexamolybdate $\left(\left[\mathrm{Mo}_{6} \mathrm{O}_{19}\right]^{2-}\right)$, heptamolybdate $\left(\left[\mathrm{Mo}_{7} \mathrm{O}_{24}\right]^{6-}\right)$, octamolybdate $\left(\left[\mathrm{Mo}_{8} \mathrm{O}_{26}\right]^{4-}\right)$, etc. Even then, this synthetic strategy allows selective isolation of only octamolybdate. We have described below the basic mechanism of this gas-liquid synthesis leading to the formation of compounds $\mathbf{1}$ and $\mathbf{2}$.

Diffusion of volatile organic amines into an aqueous acidic sodium molybdate solution occurs as mass transfer, favoured by chemical (acid-base) reaction. After diffusion occurs into the aqueous solution, the volatile organic amines react with the acidic aqueous sodium molybdate to form non-volatile ionic species consisting of protonated organic amines (for example, in the present case, pyridinium and piperidinium) as cations and octamolybdate as the common anion, which is selectively formed in the present experimental condition. The overall gas-liquid synthetic approach can be described as the mass transfer of volatile organic amine from a concentrated volatile liquid phase to the bulk liquid phase (sodium molybdate aqueous solution at a low $\mathrm{pH}$ value), in which the chemical reaction occurs. The following events are expected to occur during synthesis: (1) diffusion of volatile organic amine from a concentrated volatile liquid phase to the gas-liquid interface followed by absorption (dissolution) into the liquid (sodium molybdate aqueous solution), (2) diffusion of the reactants from the gas-liquid interface to the bulk liquid phase, (3) reaction between the dissolved volatile amine and the liquid reactant in the liquid phase occurs simultaneously with mass transfer, and (4) diffusion of the reaction products into the bulk liquid phase due to concentration gradients created by the chemical reactions, resulting in the isolation of the ion-pair products, 1 and 2.

\subsection{Description of Crystal Structures}

3.2a Crystal structure of $\left[(\text { pip } \mathrm{H})_{4}\right]\left[\mathrm{Mo}_{8} \mathrm{O}_{26}\right] \cdot 4 \mathrm{H}_{2} \mathrm{O}$ (1): In the crystal structure of compound 1, the asymmetric unit consists of half of the octamolybdate, two crystal/lattice water molecules and two piperidinium cations (Figure 1). Thus, the formula unit of 1 includes an octamolydate cluster anion, four piperidinium cations and four lattice water molecules i.e., $\left[(\mathrm{pipH})_{4}\right]\left[\mathrm{Mo}_{8} \mathrm{O}_{26}\right] \cdot 4 \mathrm{H}_{2} \mathrm{O}(\mathbf{1})$. Crystallographically, an octamolybdate anion $\left[\mathrm{Mo}_{8} \mathrm{O}_{26}\right]^{4-}$ is composed of eight edge-sharing octahedral $\left\{\mathrm{MoO}_{6}\right\}$ units. The $\{\mathrm{Mo}-\mathrm{O}\}$ groups can be classified into four categories: fourteen $\mathrm{Mo}-\mathrm{O}_{\mathrm{t}}\left(\mathrm{O}_{\mathrm{t}}=\right.$ terminal oxygen $)$ with the bond lengths in the range of $1.686-1.709 \AA$; six $\mu_{2}$-type bridged Mo $-\mathrm{O}_{\mathrm{b}}\left(\mathrm{O}_{\mathrm{b}}=\right.$ bridging oxygen $)$ with bond distances in the range of 1.747-2.269 $\AA$; four $\mu_{3}$-type bridged Mo $-\mathrm{O}_{\mathrm{b}}$ bonds that are in the range of 1.943-2.338 $\AA$ and two $\mu_{5}$-type $\mathrm{Mo}-\mathrm{O}_{\mathrm{b}}$ bonds (2.141-2.458 $\AA$ ). The structure can also be described as four $\left\{\mathrm{Mo}-\mathrm{O}_{6}\right\}$ octahedra lying above one another and joined by edgesharing.

\section{2b Hydrogen bonding situation among supramolec-} ular entities in compound 1: The crystal water/lattice water molecules $(\mathrm{O}(14)$ and $\mathrm{O}(15))$ are exclusively involved in hydrogen bonding interactions that result in a 3-D supramolecular network in the crystal structure of compound 1 . These two lattice water moleculs $(\mathrm{O}(14)$ and $\mathrm{O}(15))$ are strongly hydrogen bonded to each other within the bond limit of $2.710 \AA$ to form a supramolecular water dimer (Figure 2). One of the crystal water $\mathrm{O}(14)$ of the water dimer is again hydrogen bonded to two adjacent octamolybdate cluster anion through a terminal (from one side) oxygen atom $(\mathrm{O}(7))$ and bridging (from other side) oxygen atom $(\mathrm{O}(6))$, respectively. This results in the formation of a one-dimensional chain-like arrangement as shown in the Figure 3. Interestingly, two $\mathrm{O}(14)$ oxygen atoms (head to tail fashion) are involved in linking two cluster anions along the chain. In the crystal lattice of $\mathbf{1}$, these chains run parallel to crystallographic $a$ axis (Figure 3). 

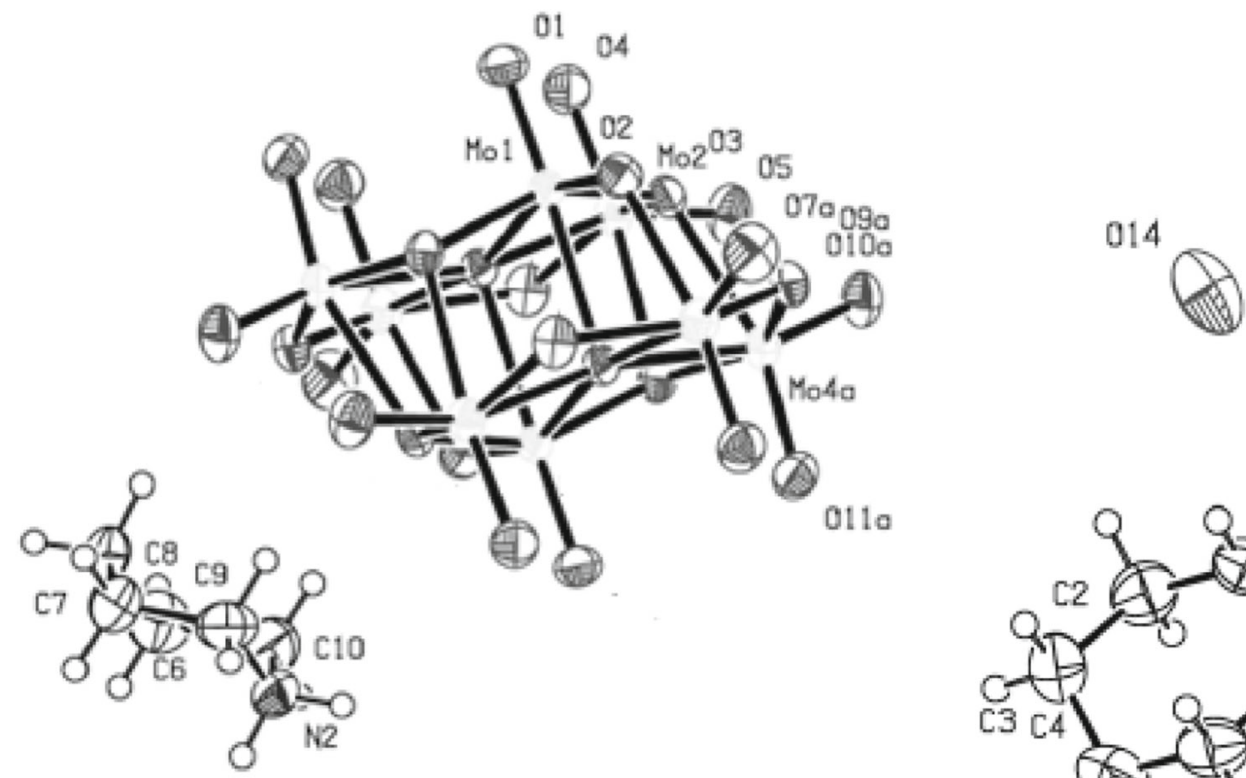

Figure 1. Thermal ellipsoid plot of compound 1 (50\% probability). Full molecule of octamolybdate is shown (in the asymmetric unit, only half of the cluster is present).
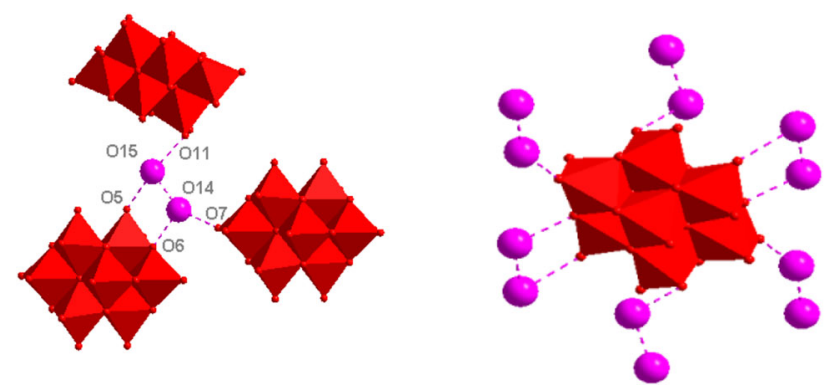

Figure 2. H-bonding environment in compound 1. left: water dimer that connects three surrounding isopolyanions; right: the isopolyanion that communicates with six surrounding water dimers.

The lattice water $\mathrm{O} 15$ is further hydrogen bonded to terminal oxygen (O11) atoms of surrounding/neighbouring isopolyanions resulting in a threedimensional supramolelcular network having well-defined channels as shown in Figure 4. In other words, these hydrogen bonding interactions are responsible for the formation of the irregular square-grids with the inner dimensions of $10.76 \times 11.57 \AA^{2}$. Interestingly, the piperidine cations are observed to reside in these channels/grids as guests (Figure 5).

The supramolecular interactions between host (formed exclusively by isopolyanions and crystal water molecules) and guests (piperidinium cations) are characterized by $\mathrm{C}-\mathrm{H} \cdots \mathrm{O}$ and $\mathrm{N}-\mathrm{H} \cdots \mathrm{O}$ hydrogen bonds, in which a piperidinium cation interacts with its surrounding isopolyanions of the host framework. Both hydrogens on $\mathrm{N}(2)$ of the piperidinium cation, undergo bifurcating hydrogen bonding interactions by donating hydrogens to four terminal oxygens $(\mathrm{O}(1), \mathrm{O}(4)$, $\mathrm{O}(8)$ and $\mathrm{O}(11)$ ), (Figure 6) from the both faces of isopolyanion with the average bond length of $2.98 \AA$ and bond angle of $132.2^{\circ}$. The relevant hydrogen bonding interactions are presented in Table S1 (Supplementary Information). The presence of the hydrogen bond donor groups like $-\mathrm{NH}_{2}-$ and $-\mathrm{CH}_{2}-$ in the piperidinium cations makes the hydrogen bonding interactions possible with both terminal and bridging oxygens of the anionic POM cluster. Interestingly, each isopolyanion, in the crystal structure interacts with 10 surrounding piperidinium cations as shown in Figure 7.

\section{2c Crystal structure of compound $\left[(\mathrm{pyH})_{4}\right]\left[\mathrm{Mo}_{8}\right.$} $\mathrm{O}_{26}$ ] (2): The compound 2 consists of two pyridine cations and half of the octamolybdate anion in its asymmetric unit as shown in Figure 8. Thus the formula unit of 2 includes an octamolybdate cluster anion and four pyridinium cations i.e., $\left[(\mathrm{pyH})_{4}\right]\left[\mathrm{Mo}_{8} \mathrm{O}_{26}\right]$ (2).

$\mathrm{C}-\mathrm{H} \cdots \mathrm{O}$ and $\mathrm{N}-\mathrm{H} \cdots \mathrm{O}$ type hydrogen bonding interactions that involve both pyridinium cation and the isopolyanion, result in a chain-like structure in compound $\mathbf{2}$ as shown in Figure 9.

The $\mathrm{C}(3)$ and $\mathrm{N}(1)$ atoms of the pyridinium cation donate their hydrogens to two terminal oxygens $\mathrm{O}(2)$ and $\mathrm{O}(13)$, respectively, from two adjacent cluster anions. Along the chain, the linking region consists of two such hydrogen bonding patterns in a head-to-tail 


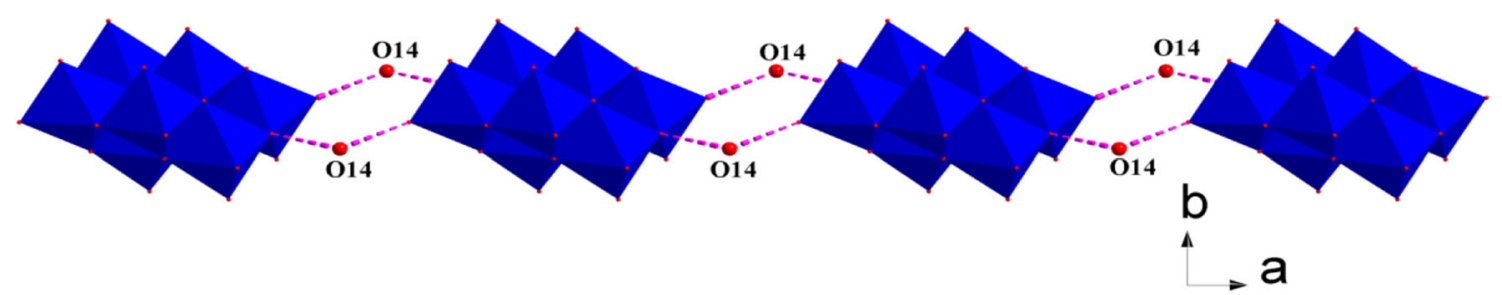

Figure 3. View of the one-dimensional chain in compound 1 looking down to the crystallographic $c$ axis. The octamolybdate (shown in polyhedra) anions are connected by the crystal water $\mathrm{O}(14)$.

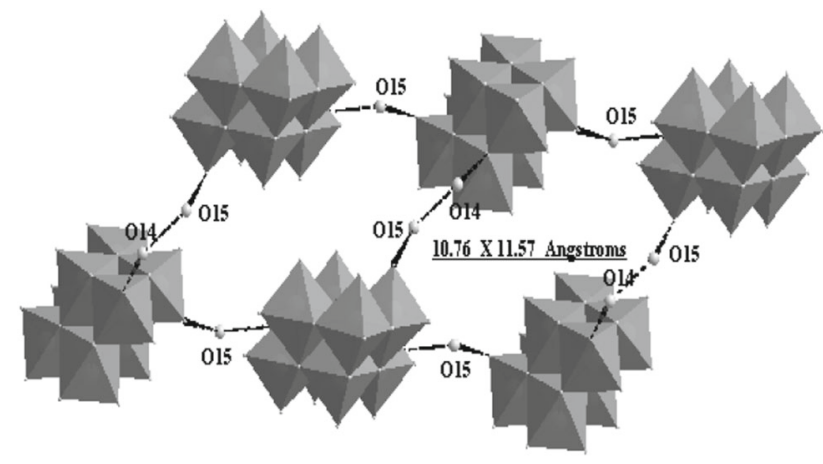

Figure 4. The square grid-type channels formed in the crystal of compound $\mathbf{1}$.

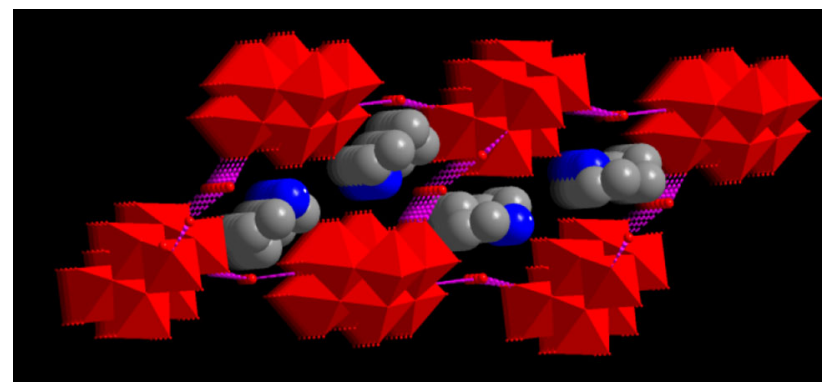

Figure 5. View of the square-grid channels in the compound $\mathbf{1}$, showing the guest piperdine molecules residing in the channels. Isopoly anion is shown in polyhedra; piperdinium cations are presented in space filling model and hydrogen bonding interactions are shown in dashed lines.

fashion making this chain a ladder type of structure (Figure 9).

These chains are then laterally linked by $\mathrm{C}-\mathrm{H} \cdots \mathrm{O}$ hydrogen bonding interactions that involve $\mathrm{O}(12)$ (a bridging oxygen of the polyainon) and $\mathrm{C}(5)$ of the pyridinium cation leading to the layer-like structure (Figure 10). In the crystal structure of compound 2, each cluster anion is surrounded by 12 pyridinium cations (Figure 11). The relevant packing diagram (compound 2) shows two types of void spaces as shown in Figure 12.

\subsection{Potential bag filter for volatile organic amines}

Many industries release volatile organic amines, that are not only harmful to human beings (carcinogenic), but

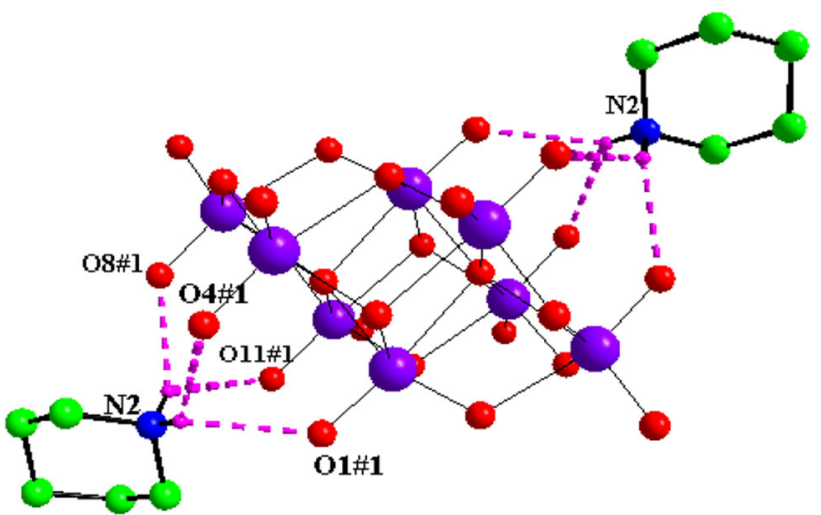

Figure 6. The bifurcation hydrogen bonding situation in compound 1. The supramolecular assembly consists of isopolyanion and piperidinium cations. Hydrogen bonding interactions are shown in dotted lines.

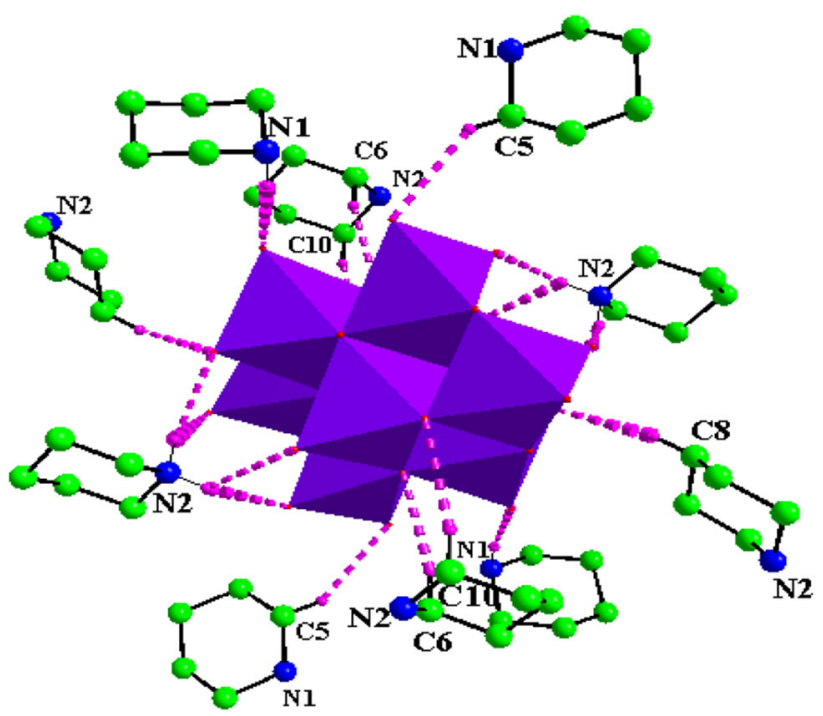

Figure 7. The hydrogen bonding interactions surrounding the isopolyanion in compound $\mathbf{1}$. The relevant hydrogen bonding parameters are presented in Table S2.

are also harmful to various animals. Moreover, gaseous organic amines are among the dreadful pollutants, due to their presence in diverse stored foods, meat, drains, etc. Thus, trapping of volatile organic amines is very important to make our environment volatile organic 
amine-free. The present work of 'gas-liquid-interface' synthesis can be described as potential bag filter for these volatile amines. Sodium molybdate and ammonium molybdate are inexpensive chemicals, present in any UG, PG and industrial laboratories, and are highly soluble in water. Adding $\mathrm{HCl}$ acid into this aqueous molybdate solution to $\mathrm{pH}$ around 2.0 can simply make this bag filter, which can capture volatile amines to form

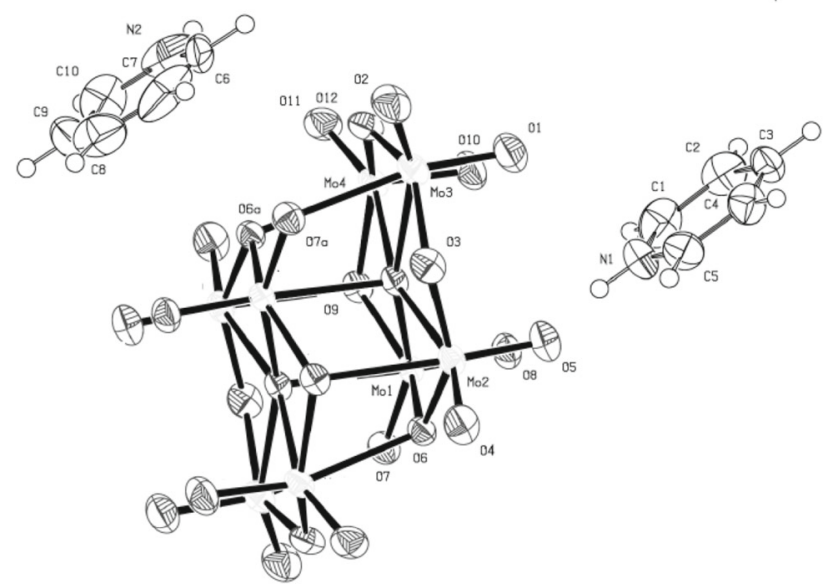

Figure 8. Thermal ellipsoid plot of compound $2(50 \%$ probability). Full molecule of octamolybdate is shown (in the asymmetric unit only half of the cluster is present). respective organic ammonium cations. These cations can be associated with in situ formed POM cluster anion (in the present study, the POM cluster anions is octamolybdate anion, $\left[\mathrm{Mo}_{8} \mathrm{O}_{26}\right]^{4-}$ ) leading to the isolation of

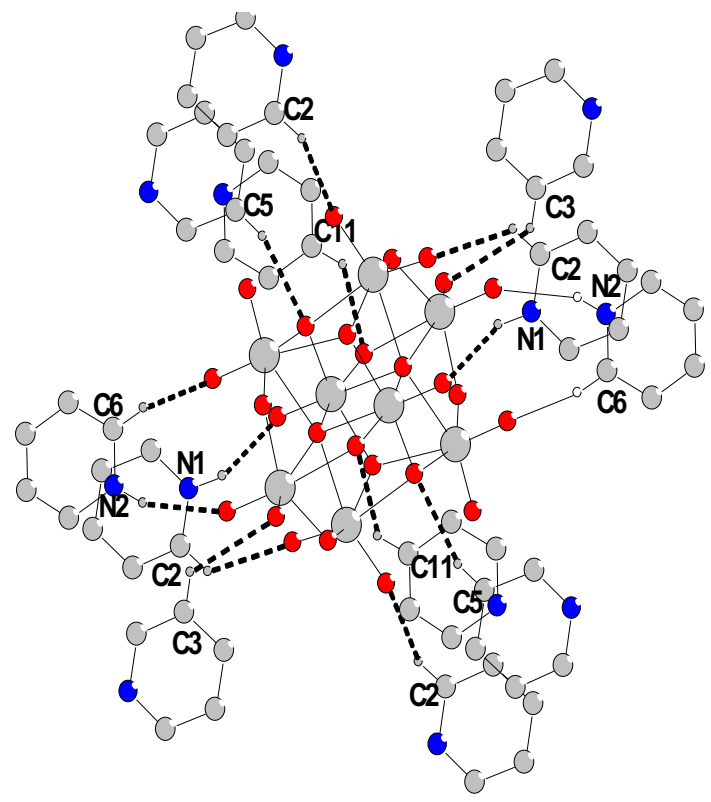

Figure 11. The isopolyanion surrounded by twelve pyridine cations via $\mathrm{C}-\mathrm{H} \cdots \mathrm{O}$ and $\mathrm{N}-\mathrm{H} \cdots \mathrm{O}$ supramoleclular interactions.

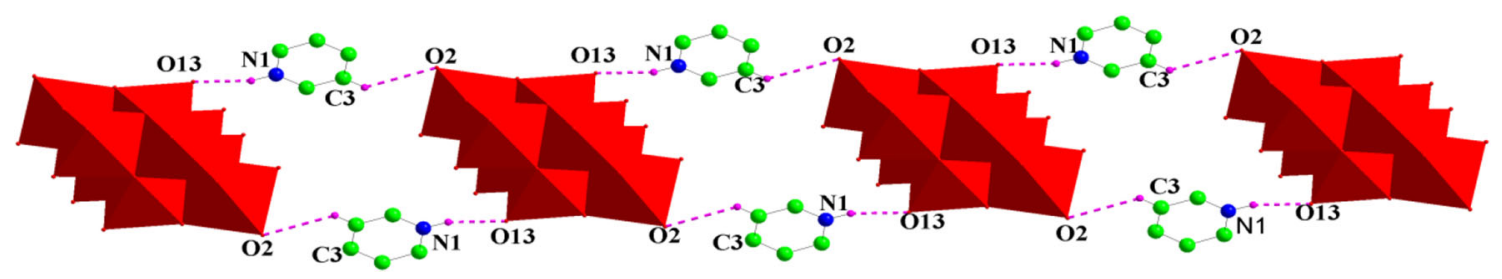

Figure 9. The hydrogen bonding interactions between the pyridinium cations and isopolyanions in compound 2. These interactions make the one-dimensional ladder-type structure.

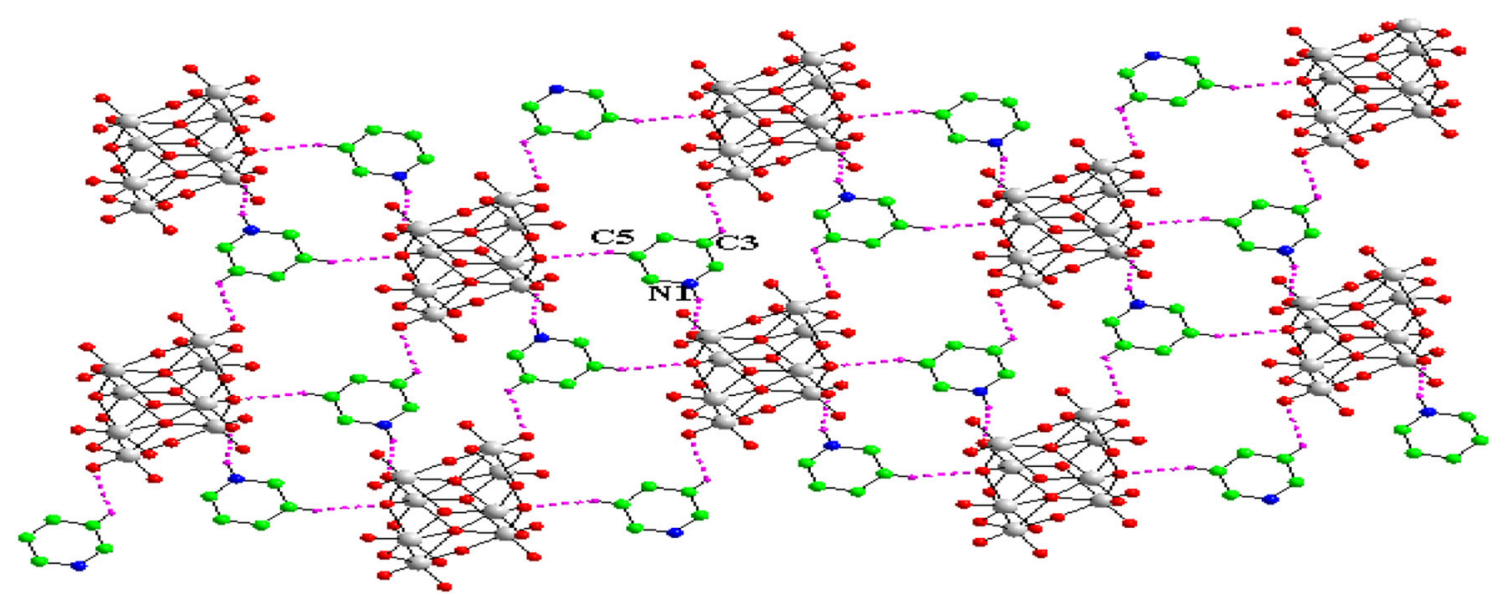

Figure 10. View illustrating hydrogen bonding situation around each pyridinium cation as well as around each POM anion in compound 2. 


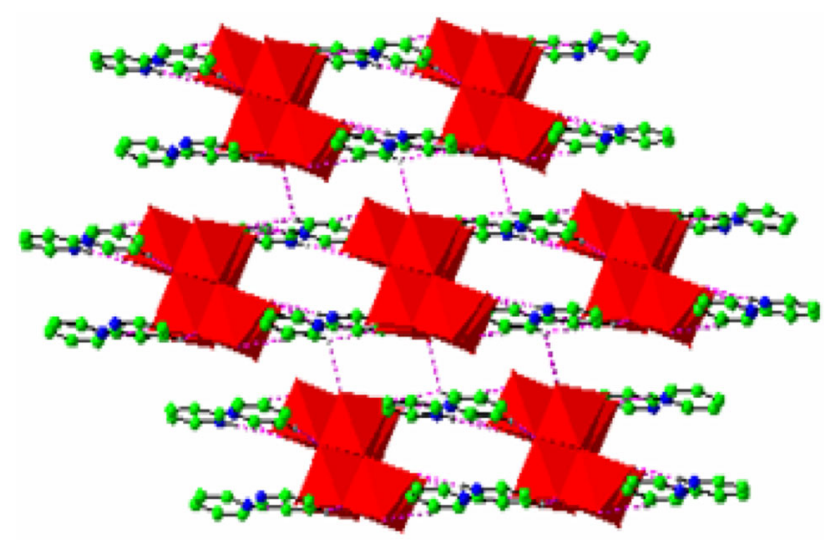

Figure 12. The packing of the cluster anions and pyridinium cations in the crystal of compound 2 , exhibiting two types of void spaces.

organic-inorganic hybrid compounds. The isolated solid (ion pair compound) is not any more volatile organic amine and thereby non-toxic.

\section{Conclusions}

Inorganic-organic hybrid materials of diverse supramolecular topologies can simply be obtained using a gas-liquid-interface reaction system by diffusion of the volatile organic amines into an aqueous POM solution at an ambient condition. This system has the potential to filter the volatile organic amines from other volatile organic substances, in which the aqueous POM solution can pick up the volatile organic amines resulting in the formation of inorganic-organic hybrid materials, viz., compounds $\mathbf{1}$ and $\mathbf{2}$ in the present work. In general, organic amines (that are severely toxic to human beings and cause CNS depression, damage to liver and kidney, etc.) have been detected around hazardous waste sites and industrial areas. We believe that the present system can be used as a potential 'bag filter' for volatile organic amines by keeping an aqueous POM solution in an environment of volatile organic amines with other volatile organic substances. This new gas-liquid synthetic strategy triggered us to isolate different POM anions as organic ammonium salts and the technical part of using this system as a 'bag filter' is in progress in our laboratory.

\section{Supplementary Information (SI)}

CCDC-1571536 and CCDC 1571537 contain the supplementary crystallographic data for compounds $\mathbf{1}$ and $\mathbf{2}$, respectively. Relevant crystal data can be obtained free of charge via http://www.ccdc.cam.atc.uk/conts/ retrieving.html, or from the Cambridge Crystallographic Data Centre, 12 Union Road, Cambridge CB2 1EZ, UK; fax: (+44) 1223-336-033; or e-mail: deposit@ccdc.cam. ac.uk. The crystallographic information for both compounds $\mathbf{1}$ and $\mathbf{2}$, including their bond lengths and angles, are given in the Supplementary Information. Supplementary Information is available at www.ias.ac. in/chemsci.

\section{Acknowledgements}

We thank the Department of Science and Technology, Government of India, for financial support (Project No. SB/IC34/2013). The National X-ray Diffractometer facility at University of Hyderabad by the Department of Science and Technology, Government of India, is gratefully acknowledged. We acknowledge UGS-CAS, DST-PURSE and DST-FIST. V. S. and N. T. K. thank CSIR, New Delhi for their fellowships.

\section{References}

1. (a) Pope M T and Müller A 1991 Polyoxometalate chemistry: an old field with new dimnsions in several disciplines Angew. Chem. Int. Ed. Engl. 30 34; (b) Müller A, Peters, M T and Pope D 1989 Gatteschi, Polyoxometalates: very large clusters nanoscale magnets Chem. Rev. 98 239; (c) Pope M T 1983 Heteropoly and isopoly oxometalates (Berlin: Springer-Verlag); (d) Katsoulis D E 1998 A survey of applications of polyoxometalates Chem. Rev. 98359

2. (a) Klemperer W G and Wakk C G 1998 Polyoxoanion moves toward future Chem. Rev. 98 297; (b) Coronado E and Gomez-Garcia C J 1998 Polyoxometalate based molecular materials Chem. Rev. 98 273; (c) Jeanin Y P 1998 The nomenclature of polyoxometalates: how to connect a name and a structure Chem. Rev. 98 51; (d) Baker L C W and Glick D C 1998 Present general status of understanding of heteropoly electrolytes Chem. Rev. 98 3; (e) Cronin L, Kögerler P and Müller A 2000 Controlling growth of novel solid-state materials via discrete molybdenum-oxide-based building blocks as synthons J. Solid State Chem. 152 57; (f) Roy S, Sarkar S, Pan J, Waghmare U V, Dhanya R, Narayana C and Peter S C 2016 Crystal Structure and Band Gap Engineering in Polyoxometalate Based Inorganic-Organic Hybrids Inorg. Chem. 55 3364; (g) Iyer A K and Peter S C 2014 Two Dimensional Bicapped Supramolecular Hybrid Semiconductor Material Constructed from the Insulators $\alpha$-Keggin Polyoxomolybdate and 4, 4'Bipyridine Inorg. Chem. 53 653; (h) Iyer A K, Roy S, Haridasan R, Sarkar S and Peter S C 2014 Ligand mediated valence fluctuation of copper in new hybrid materials constructed from decavanadate and $\mathrm{Cu}(1,10$ phenanthroline) complex Dalton Trans. 432153

3. (a) Ishii Y, Takenaka Y and Konishi K 2004 Porous organic-inorganic assemblies constructed from Keggin polyoxometalate anions and calix[4]arene- $\mathrm{Na}^{+}$complexes: structures and guestsorption profiles Angew. Chem. Int. Ed. Engl. 43 2702; (b) Pavani K, Lofland S E, Ramanujachary K V and Ramanan A 2007 The hydrothermal synthesis of transition metal complex 
template octamolybdates Eur. J. Inorg. Chem. 568; (c) Thomas J and Ramanan A 2008 Growth of copper pyrazaole complex templated phosphomolybdate: supramolecular interactions dictate nucleation of a crystal Cryst. Growth Des. 8 3390; (d) Singh M, Lofland S E, Ramanujachary K V and Ramanan A 2010 Crystallization of Anderson-Evans type chromium molybdate solids incorporated with a metal pyrazine complex or coordination polymer Cryst. Growth Des. 10 5105; (e) Singh M and Ramanan A 2011 Crystal engineering of polyoxomolybdate based metal-organic solids: the case of chromium molybdate cluster based metal complexes and coordination polymers Cryst. Growth Des. 113381

4. Miras H N, Vila-Nada L and Cronin L 2014 Polyoxometalate based open-frameworks Chem. Soc. Rev. 43 5679

5. Du D, Qin J, Li S, Su Z and Lan Y 2014 Recent advances in porous polyoxometalate based metal-organic frameworks Chem. Soc. Rev. 434615

6. (a) Yaun M, Li Y, Wang E, Tian C, Wang L, Hu N and Jia H 2003 Modified polyoxometalates: hydrothermal syntheses and crystal structures of three novel reduced and capped Keggin derivatives decorated by transition metal complexes Inorg. Chem. 42 3670; (b) $\mathrm{Xu} \mathrm{Y,} \mathrm{Xu} \mathrm{J-Q,} \mathrm{Zhang} \mathrm{K-L,} \mathrm{Zhang} \mathrm{Y} \mathrm{and} \mathrm{You}$ X-Z 2000 Keggin unit supported transition metal complexes: hydrothermal synthesis and characterization of $\left[\mathrm{Ni}\left(2,2^{\prime} \text { bipy }\right)_{3}\right]_{1.5}\left[\mathrm{PW}_{12} \mathrm{O}_{40} \mathrm{Ni}\left(2,2^{\prime}-\right.\right.$ bipy $\left.)_{2}\left(\mathrm{H}_{2} \mathrm{O}\right)\right] \cdot 0.5 \mathrm{H}_{2} \mathrm{O}$ and $\left[\mathrm{Co}\left(1,10^{\prime}-\right.\right.$ phen $\left.)_{3}\right]_{1.5}\left[\mathrm{PMo}_{12} \mathrm{O}_{40} \mathrm{Co}\left(1,10^{\prime}-\text { phen }\right)_{2}\left(\mathrm{H}_{2} \mathrm{O}\right)\right]$. $0.5 \mathrm{H}_{2} \mathrm{O}$. Chem. Commun. 153; (c) Zapf P J, Warren C J, Haushalter R C and Zubieta J 1997 Oneand two-dimensional organic-inorganic composite solids constructed from molybdenum oxide clusters and chains linked through $\left\{\mathrm{M}\left(2,2^{\prime}-\text { bpy }\right)\right\}^{2+}$ fragments $(\mathrm{M}=\mathrm{Co}, \mathrm{Ni}, \mathrm{Cu})$ Chem. Commun. 1543; (d) Khan M I, Yohannes E and Doedens R J 2003 A novel series of materials composed of arrays of vanadium oxide container molecules, $\left\{\mathrm{V}_{18} \mathrm{O}_{42}(\mathrm{X})\right\}(\mathrm{X}=$ $\left.\mathrm{H}_{2} \mathrm{O}, \mathrm{Cl}^{-}, \mathrm{Br}^{-}\right)$: synthesis and characterization of $\left.\left[\mathrm{M}_{2} \mathrm{H}_{2} \mathrm{~N}\left(\mathrm{CH}_{2}\right)_{2} \mathrm{NH}_{2}\right)_{5}\right]\left[\left\{\mathrm{M}\left(\mathrm{H}_{2} \mathrm{~N}\left(\mathrm{CH}_{2}\right)_{2} \mathrm{NH}_{2}\right)_{2}\right\}_{2} \mathrm{~V}_{18}\right.$ $\left.\mathrm{O}_{42}(\mathrm{X})\right] \cdot 9 \mathrm{H}_{2} \mathrm{O}(\mathrm{M}=\mathrm{Zn}, \mathrm{Cd})$. Inorg. Chem. 42 3125; (e) Hagrman D, Zapf P J and Zubieta J 1998 A two-dimensional network constructed from hexamolybdate, octamolybdate and $\left[\mathrm{Cu}_{3}(4,7-\text { phen })_{3}\right]^{3+}$ clusters: $\left[\left\{\mathrm{Cu}_{3}(4,7-\text { phen })_{3}\right\}_{2}\left\{\mathrm{Mo}_{14} \mathrm{O}_{45}\right\}\right]$ Chem. Commun. 1283; (f) Lin B Z and Liu S X 2002 First hexadecavanadate compound: hydrothermal synthesis and characterization of a three-dimensional framework $\left[\left\{\mathrm{Cu}(1,2-\mathrm{pn})_{2}\right\}_{7}\left\{\mathrm{~V}_{16} \mathrm{O}_{38}\left(\mathrm{H}_{2} \mathrm{O}\right)\right\}_{2}\right] \cdot 4 \mathrm{H}_{2} \mathrm{O}$ Chem. Commun. 2126; (g) Hagrman D, Zubeita C, Rose D J, Zubieta J and Haushalter R C 1997 Composite solids constructed from one-dimensional coordination polymer matrices and molybdenum oxide subunits: polyoxomolybdate clusters within $\left[\left\{\mathrm{Cu}\left(4,4^{\prime}-\text { bpy }\right)\right\}_{4} \mathrm{Mo}_{8} \mathrm{O}_{26}\right]$ and $\left[\left\{\mathrm{Ni}\left(\mathrm{H}_{2} \mathrm{O}\right)_{2}\left(4,4^{\prime}-\right.\right.\right.$ bpy $\left.)_{2}\right\}_{2} \mathrm{Mo}_{8} \mathrm{O}_{26}$ ] and one-dimensional oxide chains in $\left[\left\{\mathrm{Cu}\left(4,4^{\prime}-\text { bpy }\right)\right\}_{4} \mathrm{Mo}_{15} \mathrm{O}_{47}\right] \cdot 8 \mathrm{H}_{2} \mathrm{O}$ Angew. Chem. Int. Edit. 36873

7. (a) Grüttner B and Jander G 1962 Handbuch der Präparativen Anorganischen Chemie 2nd ed. (Stuttgart: Enke Verlag); (b) Khan M I and Zubieta J 1995 Oxovanadium and oxoolybdenum clusters and solids incorporating oxygen-donor ligands In Progress In Inorganic Chemistry Kenneth D Karlin (Ed.) Vol. 42 p. 1 (New York: John Wiley and Sons)

8. (a) Yamase T 1998 Photo- and electrochromism of polyoxometalates and related materials Chem. Rev. 98 307; (b) Kumar A, Gupta A K, Devi M, Gonsalves K E and Pradeep C P 2017 Engineering multi-functionality in hybrid polyoxometalates: aromatic sulfonium octamolybdates as excellent photochromic materials and self-separating catalysis for epoxidation Inorg. Chem. 56 10325; (c) Kumar A, Bevi M, Mamidi N, Gonsalves K E and Pradeep C P 2015 Aromatic sulfonium polyoxometalates: a new class of solid state photochromic materials with tunable properties Chem. Eur. J. 21 18557; (d) Kalyani V, Satyanarayana V S V, Sarkar A S, Kumar A, Pal S K, Ghosh S, Gonsalves K E and Pradeep C $P 2015$ A radiation sensitive hybrid polymer based on Mn-Anderson polyoxometalate cluster and a UV activeorganic monomer: synergistic effects leads to improved photocurrent in a photoresponsive device $R S C A d v .5$ 36727; (e) Sahasrabudhe A and Roy S 2014 Photoactive gold nanoparticle softoxometalates (SOM) using a Keplerate for synthesis of polystyrene latex microspheres by photo-polymerization J. Mol. Eng. Mater. 2 1440002; (f) Das S, Misra A and Roy S 2016 Photo Redox Mediated Inexpensive One-Pot Synthesis of 1,4Diphenyl Substituted Butane-1,4-Dione from Styrene using Polyoxometalates as Catalysts ChemistrySelect. 1 691; (g) Das S, Biswas S, Balaraju T, Barman S, Pochamoni R and Roy S 2016 Photochemical Reduction of Carbon Dioxide Coupled with Water Oxidation using Various Soft-oxometalate (SOM) based Catalytic Systems J. Mater. Chem. A 48875

9. "Pyridine" IARC Monographs 771985 Washington DC: OSHA

10. (a) Record of Pyridine, in the GESTIS Substance database of the IFA; (b) International Agency for Research in Cancer (IARC) Summaries and Evaluations 2007 IPCS INCHEM; (c) Bonnard N, Brondeau M T, Miraval S, Pilliere F, Protois J C and Schneider O 2001 Pyridine Fiche Toxicologique 85 1-5 (INRS); (d) Junk G A and Ford C S 1980 A review of organic emissions from selected combustion processes Chemosphere 9 187; (e) Clayton G D and Clayton F E 1993-1994 Patty's Industrial Hygiene and Toxicology Vol. 2A, 2B, 2C, 2D, 2E, $2 F$ : Toxicology 4th edn. (New York, NY: John Wiley \& Sons Inc.)

11. Gao T, Tillman E S and Lewis N S 2005 Detection and classification of volatile organic amines and carboxylic acids using arrays of carbon black-dendrimer composite vapor detectors Chem. Mater. 172904

12. Seesaard T, Lorwongtragool $\mathrm{P}$ and Kerdcharoen $\mathrm{T}$ 2015 Development of fabric-based chemical gas sensors for use as wearable electronic noses Sensors 15 1885

13. Ramos C X, Estévez S L and Giraldo E 2002 Removal of pyrene by different microalgal species Water Sci. Technol. 46195

14. Rai P, Majhi S M, Yu Y T and Lee J H 2015 Synthesis of plasmonic Ag@ $\mathrm{SnO}_{2}$ core-shell nanoreactors for xylene detection RSC Adv. 517653 
15. Mochalski P, King J, Klieber M, Unterkofler K, Hinterhuber H, Baumann M and Amann A 2013 Blood and breath levels of selected volatile organic compounds in healthy volunteers Analyst 1382134

16. Mazzatenta A, Pokorski M, Sartucci F, Domenici L and Giulio C D 2015 Volatile organic compounds (VOCs) fingerprint of Alzheimer's disease Respir. Physiol. Neurobiol. 20981

17. Liu B, Zhang L, Zhao H, Chen Y and Yang H 2012 Synthesis and sensing properties of spherical flowerlike architectures assembled with $\mathrm{SnO}_{2}$ submicron rods Sensor Actuat B-Chem. 173643

18. Guo T, Luo Y, Zhang Y, Lin Y-H and Nan C-W 2014 $\mathrm{ZnO}-\mathrm{NiO}$ hetero-nanostructures as highly sensitive and selective triethylamine sensor J. Appl. Phys. 116044309

19. Tomer V K, Devi S, Malik R, Nehra S P and Duhan S 2016 Highly sensitive and selective volatile organic amine (VOA) sensors using mesoporous $\mathrm{WO}_{3}-$ $\mathrm{SnO}_{2}$ nanohybrids Sensor Actuat B-Chem. 229321

20. (a) Eda $\mathrm{K}$ and Iriki Y 2005 Crystal Engineering with $\left[\mathrm{Mo}_{36} \mathrm{O}_{112}\left(\mathrm{H}_{2} \mathrm{O}\right)_{16}\right]^{8-}$ Anion as Nanosized Building Block Chem. Lett. 34 612; (b) Krebs B and Boschen I P 1982 The structure of the potassium isopolymolybdate $\mathrm{K}_{8}\left[\mathrm{Mo}_{36} \mathrm{O}_{12}\left(\mathrm{H}_{2} \mathrm{O}\right)_{16}\right] \cdot n \mathrm{H}_{2} \mathrm{O}(n=36 \ldots 40)$ Acta Crystallogr. B 381710

21. (a) McCann M and Maddock K 1994 Synthesis and reactions of $\left[\mathrm{Et}_{3} \mathrm{NH}\right]_{4}\left[\mathrm{Mo}_{8} \mathrm{O}_{6}\right]$ : X-ray crystal structure of $\left[\mathrm{Et}_{3} \mathrm{NH}\right]_{3}\left[\mathrm{NaMo}_{8} \mathrm{O}_{26}\right]$ Polyhedron 13 835; (b) McCarron E M, Whitney J F and Chase D B 1984 Pyridinium molybdates. Synthesis and structure of an octamolybdate containing coordinately bound pyridine: $\left[\left(\mathrm{C}_{5} \mathrm{H}_{5} \mathrm{~N}\right)_{2} \mathrm{Mo}_{8} \mathrm{O}_{26}\right]^{4-}$ Inorg. Chem. 23 3275; (c) Modec M, Brenčič J V and Zubieta J 2003 The solvatothermal synthesis and the crystal structure of polymeric $N$-methylpyridinium octamolybdate(VI), (Me $\left.\mathrm{NC}_{5} \mathrm{H}_{5}\right)_{4 n}\left[\mathrm{Mo}_{8} \mathrm{O}_{26}\right]_{n}$ Inorg. Chem. Commun. 6 506; (d) Pan C-L, Song J-F, Xu J-Q, Li G-H, Ye L and Wang T-G 2003 Three-Dimensional open-framework cobalt-molybdenum phosphate by hydrothermal synthesis: $\left(\mathrm{C}_{2} \mathrm{H}_{9} \mathrm{~N}_{2}\right)_{4}\left(\mathrm{C}_{2} \mathrm{H}_{10} \mathrm{~N}_{2}\right)\left[\mathrm{Co}_{3} \mathrm{Mo}_{4} \mathrm{P}_{4} \mathrm{O}_{28}\right]$ Inorg. Chem. Commun. 6 535; (e) Niu J-Y, Wei M-L, Wang J-P and Dong D-B 2003 Synthesis and crystal structure of 1D polyoxometalate-based composite compound, $\left[\left\{\mathrm{Gd}(\mathrm{NMP})_{6}\right\}\left(\mathrm{PMo}_{12} \mathrm{O}_{40}\right)\right]_{n}(\mathrm{NMP}=$ $N$-methyl-2-pyrrolidone) J. Mol. Struct. 655171

22. (a) Fuchs J and Hartl H 1976 Anion structure of tetrabutyl ammonium octamoybdate $\left[\mathrm{N}\left(\mathrm{C}_{4} \mathrm{H}_{9}\right)_{4}\right]_{4} \mathrm{Mo}_{8} \mathrm{O}_{26}$ Angew. Chem. Int. Ed. Engl. 15 375; (b) Bharadwaj P K, Ohashi Y, Sasadi Y, Sasaki Y and Yamase T 1984 Structure ofoxonium tris-(tri-ethylammonium) octamolybdate(4-) dihydrate, $\left(\mathrm{C}_{6} \mathrm{H}_{16}\right)_{3}\left(\mathrm{H}_{3} \mathrm{O}\right)\left[\mathrm{Mo}_{8} \mathrm{O}_{26}\right] \cdot 2 \mathrm{H}_{2} \mathrm{O}$ Acta Cryst. Sect. C 40 48; (c) Hsieh T and Zubieta J 1985 Synthesis and characterization of oxomolybdate clusters containing co-ordinatively bound diazenido units. The crystal and molecular structur of the octanuclear oxomolybdate $\left(\mathrm{NHEt}_{3}\right)_{2}\left(\mathrm{NBu}_{4}\right)_{2}\left[\mathrm{Mo}_{8} \mathrm{O}_{20}(\mathrm{NNPh})_{6}\right]$ J. Chem. Soc. Chem. Commun. 1749; (d) Roman P, Gutierrez-Zorilla
J M, Martinz-Rippol M and Garcia-Blanco S 1986 Structure of 2-methyl-pyridinium $\beta$-octamolybdate(VI) Acta Cryst. Sect. C 42 956; (e) Hsieh T, Shaikh S N and Zubieta J 1987 Derivatized polyoxomolybdates. Synthesis and characterization of oxomolybdate clusters containing coordinatively bounddiazenido units. Crystal and molecular structure of the octanuclear oxomolybdate $\left(\mathrm{NHEt}_{3}\right)_{2}\left(\mathrm{n}-\mathrm{Bu}_{4} \mathrm{~N}\right)_{2}\left[\mathrm{Mo}_{8} \mathrm{O}_{20}(\mathrm{NNPh})_{6}\right]$ and comparison to the structures of the parent oxomolybdate alpha.- $\left(\mathrm{n}-\mathrm{Bu}_{4} \mathrm{~N}\right)_{4}\left[\mathrm{Mo}_{8} \mathrm{O}_{26}\right]$ and the tetranuclear (diazenido)oxomolybdates $\left(\mathrm{n}-\mathrm{Bu}_{4} \mathrm{~N}\right)_{2}\left[\mathrm{Mo}_{4} \mathrm{O}_{10}(\mathrm{OMe})_{2}(\mathrm{NNPh})_{2}\right]$ and $\left(\mathrm{n}-\mathrm{Bu}_{4} \mathrm{~N}\right)_{2}\left[\mathrm{Mo}_{4} \mathrm{O}_{8}(\mathrm{OMe})_{2}\left(\mathrm{NNC}_{6} \mathrm{H}_{4} \mathrm{NO}_{2}\right)_{4}\right] \quad$ Inorg. Chem. 26 4079; (f) McCann M, Maddock K, Cardin C, Convery M and Ferguson G 1995 Synthesis and X-ray crystal structure of the triethylammonium magnesium $\beta$-octamolybdate(VI) salt $\left[\mathrm{Et}_{3} \mathrm{NH}\right]_{2}\left[\mathrm{Mg}\left(\mathrm{H}_{2} \mathrm{O}\right)_{6} \mathrm{Mo}_{8} \mathrm{O}_{26}\right] \cdot 2 \mathrm{H}_{2} \mathrm{O}$ Polyhedron 14 3655; (g) Wang X-J, Kang B S, Su C Y, Yu K B, Zhang $\mathrm{H} X$ and Chen Z N 1999 Function of the hydrogen bond in the conversion of $\alpha$ - to $\beta-\mathrm{Mo}_{8} \mathrm{O}_{26}^{4-}$ ions: Formation and structure of tetra(tributylhydrogenammonium) $\beta$-octamolybdate Polyhedron 183371

23. (a) Xu X-X and You Z-X 1994 The crystal structure of tetra(piperidinium) octamoybdate(VI) tetrahydrate Polyhedron 13 1011; (b) Kaziev G Z, Dutov A A, Quynones S H, Belsky, Zavodnik V E and Karamnov M A 2003 X-Ray Diffraction Study of Piperidine Octamolybdate J. Struct. Chem. 44889

24. Ding Y, Lu F and Han X 2012 Study on Catalytic oxidation of benzaldehyde to benzoic acid with keggin polyoxometalate $\left[\left(\mathrm{CH}_{2}\right)_{5} \mathrm{NH}_{2}\right]_{4} \mathrm{SiW}_{12} \mathrm{O}_{40}$ Appl. Mech. Mater. 161185

25. (a) Miao H, Dong Y, Chen Z, He X, Hu G and Xu Y 2016 Design, synthesis and excellent third-order NLO properties of two new polyoxometalates constructed from Keggin polyanions bonded by a solvent molecule Dalton Trans. 45 12717; (b) Emirdag-Eanes M, Onen B and McMillen D 2015 Hydrothermal synthesis and characterization of one dimensional chain structures of monolacunary Keggin polyoxoanions substituted with copper Inorg. Chim. Acta 427 219; (c) Liu T and Hou J H 2014 Direct hydroxylation of benzene to phenol over pyridine-modified vanadium-substituted heteropoly acid under microwave condition Asian J. Chem. 26 2683; (d) Liu X, Nie H, Wang L and Huang R 2013 Three inorganic-organic hybrid compounds based on Keggin polyoxometalate and transition metal complexes: crystal structures and electrochemical properties J. Coord. Chem. 66444

26. SAINT 1998 Software for the CCD Detector System; Bruker Analytical X-ray Systems, Inc.: Madison, WI

27. Sheldrick G M 1997 SHELXS-97, Program for Structure Solution; University of Gottingen: Gottingen, Germany

28. Sheldrick G M 1997 SHELXL-97, Program for Crystal Structure Analysis; University of Gottingen: Gottingen, Germany 